
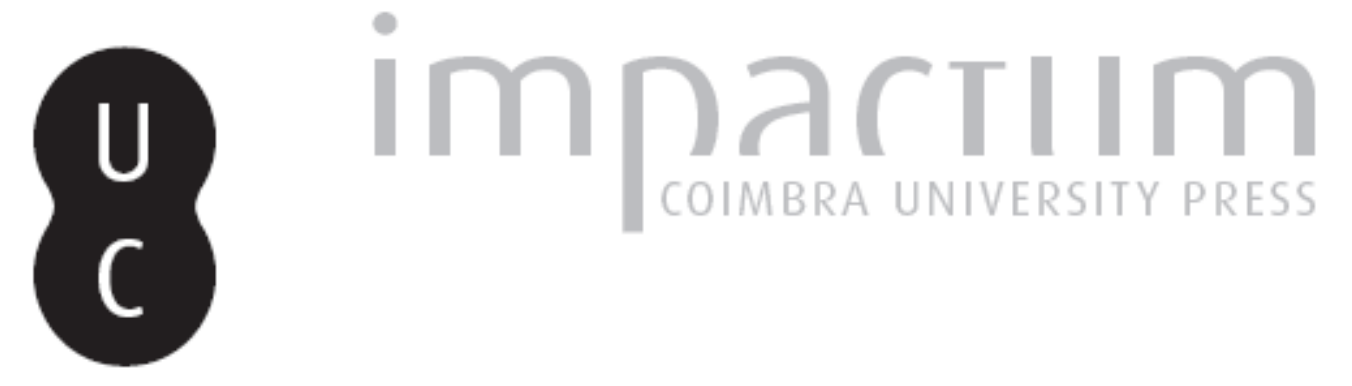

\title{
Um confronto metodológico no diálogo islamo-cristão medieval: Raimundo Martí e Raimundo Lulo
}

\author{
Autor(es): $\quad$ Lavajo, Joaquim Chorão
}

Publicado por: Imprensa da Universidade de Coimbra

URL persistente:

URI:http://hdl.handle.net/10316.2/43933

DOI:

DOl:https://doi.org/10.14195/2183-8925_3_9

Accessed : $\quad$ 26-Apr-2023 13:00:22

A navegação consulta e descarregamento dos títulos inseridos nas Bibliotecas Digitais UC Digitalis, UC Pombalina e UC Impactum, pressupõem a aceitação plena e sem reservas dos Termos e Condições de Uso destas Bibliotecas Digitais, disponíveis em https://digitalis.uc.pt/pt-pt/termos.

Conforme exposto nos referidos Termos e Condições de Uso, o descarregamento de títulos de acesso restrito requer uma licença válida de autorização devendo o utilizador aceder ao(s) documento(s) a partir de um endereço de IP da instituição detentora da supramencionada licença.

Ao utilizador é apenas permitido o descarregamento para uso pessoal, pelo que o emprego do(s) título(s) descarregado(s) para outro fim, designadamente comercial, carece de autorização do respetivo autor ou editor da obra.

Na medida em que todas as obras da UC Digitalis se encontram protegidas pelo Código do Direito de Autor e Direitos Conexos e demais legislação aplicável, toda a cópia, parcial ou total, deste documento, nos casos em que é legalmente admitida, deverá conter ou fazer-se acompanhar por este aviso.

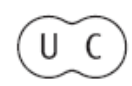




\section{REVISTA DE HISTORIA DAS IDEIAS}

Volume III

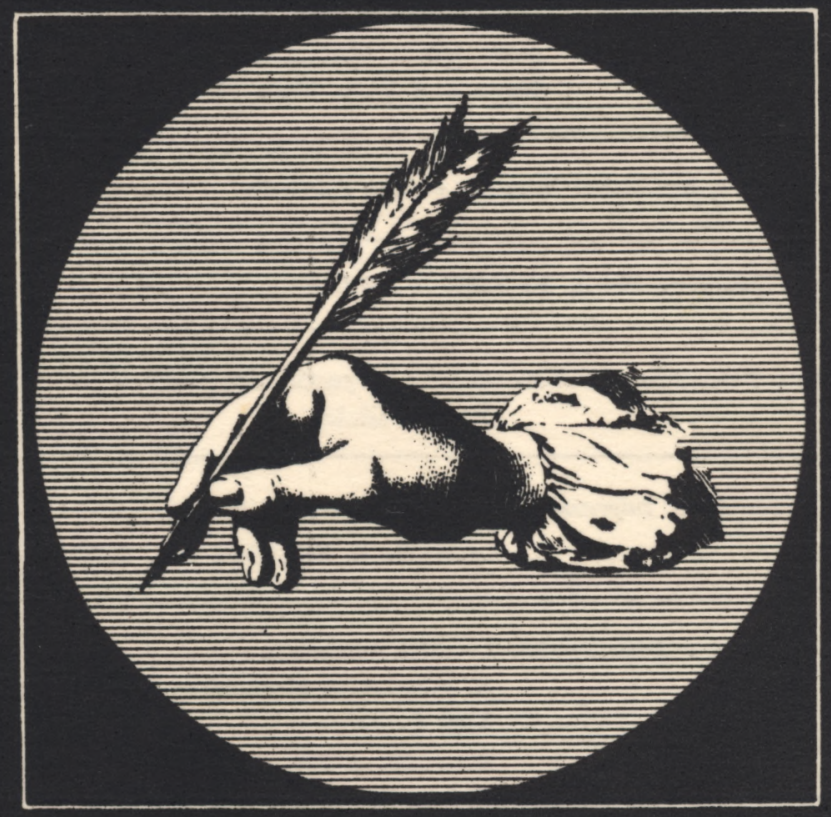

INSTITUTO DE HISTÓRIA E TEORIA DAS IDEIAS

$$
\begin{gathered}
\text { FACULDADE DE LETRAS } \\
\text { COIMBRA } 1981
\end{gathered}
$$




\section{UM CONFRONTO METODOLÓGICO NO DIÁLOGO ISLAMO-CRISTÃO MEDIEVAL RAIMUNDO MARTÍ E RAIMUNDO LULO}

É Raimundo Lulo um personagem religiosa e intelectualmente enigmático. No seu carácter tão contrastante se fundamenta a disparidade de apreciaçðes com que os historiadores tentam apresentá-lo. Para uns, não passa de um homem medíocre, psiquicamente desequilibrado; para outros, o seu valor é tal, que atinge as raias da genialidade. Para os primeiros, Lulo não passa de um filósofo mediano com assomos de megalomania e intolerância: «Ce courreur d'aventures, ce fanatique cet halluciné ne peut pas être compté parmi les philosophes scolastiques... On a conservé plusieurs de ses écrits où, non content de maudire les gens qui ne pensaient pas comme lui, il appelait sur leurs têtes les foudres de l'Église et le glaive de l'autorité séculière. Qu'on le comprenne bien, ces gens qu'il vouait en sa fureur aux flammes vengeresses, c'étaient de modestes thomistes, qu'il dénonçait comme sectateurs d'Averröes. La modestie, la réserve, la prudence, l'indignaient; elles étaient pour lui les indices de quelque sorte de complicité secrete» (1).

Para os segundos, Lulo é um homem polivalentemente superior: "Altri già ce lo illustrarono bellamente e come teologo non mediocre, e come mistico infiamato, filosofo sottile, apollogista abile, e specialmente come poeta e romanziere classico, riconosciuto perciò da tutti come il padre del romanzo e della poesia catalana» (2).

Duas perspectivações divergentes da personalidade luliana. A interpretação da Histoire Littéraire de la France é demasiado preconcebida e exaltada para que possa ser justa; combate o fanatismo de Lulo com

(4) Bernard Hauréau, in Histoire Littéraire de la France, t. 25, Paris 1885, pp. 1-386;

(2) P. Girolamo Golubovich, O.F.M, Biblioteca Bio-Bibliografica, t. 1, Firenze 1906, p. 362; 
outro fanatismo não menor. A interpretação assumida por Golubovich é objectiva no que diz, mas tendenciosa pelo que não diz. Há que expôr os defeitos sem esquecer as virtudes. Há que sublinhar que «la objectividad de la narración, como adverte Batllori, no impide... que, en momentos de crisis, Ramón convierta en realidad objectiva lo que él veía en sus exaltaciones y en sus depresiones psíquicas» (1).

É com este critério de objectividade e serenidade que queremos interpretar o método luliano em relação à conversão dos infiéis e compará-lo ao por ele tão criticado método de Ramón Martí, que outra coisa não é que o método dominicano.

Após a conversão, Lulo deixou-se absorver totalmente por um ideal: o da salvação dos infiéis. Estava convencido de que a conversão dos infiéis em geral e a dos muçulmanos em especial, devia passar, quase exclusivamente, pela argumentação racional e, após a constatação da ineficácia desta, pela luta armada. Segundo ele, para atingir esse objectivo, todos os outros meios, inclusivé a persuasão pela fé, em que vivencialmente apoiava o seu relacionamento pessoal com Deus, eram ineficazes ou insuficientes. Consciente de que era um espírito intelectualmente privilegiado, pensou escrever um livro, o melhor do mundo, contra os erros dos infiéis» (2). Essa ideia acompanhou-o durante nove anos, até que um dia se sentiu inspirado por Deus para o fazer (3). Deixou a solidão de Randa e, no mosteiro de La Real, pôs mãos à obra. Assim surgiu o que primeiro chamou Arte Maior e depois Arte Geral (4).

Lulo tinha encontrado o objecto e o método a que consagraria toda a sua existência. Estava convencido de que ele, e só ele, possuia a chave mágica da conversão dos infiéis. Nos seus ímpetos incontrolados de zelo apostólico, sobre um fundo de humildade e pessimismo

(1) Miguel Batllori, S.J., Introd. à Vida Coetanea, in Antologia de Ramon Lull, vol. 1, Madrid 1961, p. 51-52;

(2) «...intravit cor ejus vehemens ac implens quoddam dictamen mentis, quod ipse facturus esset postea unum librum, meliorem de mundo, contra errores indifelium». Vita Coetanea, in Raimundi Lulli Opera Latina (ap. Corpus Christianorum, t. 34), Turnholti 1980, p. 275.

(3) «Subito Dominus illustravit mentem suam, dans eidem formam et modum faciendi librum de quo supra dicitur contra errores infidelium». Vit. Coet., ed. cit., 280;

(4) «Coepit ibidem ordinare et facere librum illum, vocans ipsum primo: Artem Maiorem, sed postea: Artem Generalem». Ib. 
radicais, lança frequentemente para o papel a convicção de ter encontrado a solução última para todos os problemas intelectuais e apostólicos. Os esquemas mentais em que se desenrola a sua actuação ofuscam-no de tal maneira que o impedem de reconhecer outros possíveis processos de igual ou superior valor. Este radicalismo será a causa da insatisfação interior que o corrói e que não consegue conter. De entre muitos textos em que exprime essa angústia interior, citamos um que diz ter escrito na noite de Natal de 1310, em idade já bastante avançada: «Heu mihi! In quanta angustia sum positus, tristis, flens et dolosus, solus, impotens et antiquus, et quasi ab omnibus vilipensus...

...Sum tristis et languidus et multo languore plenus, quia quod scio philosophicum vel theologicum, altum et sublime, ad confutendum errores infidelium et solvendum dicta erronea contra fidem per Artem Generalem, quam habeo Dei gratia mediante, nullum quasi invenio, qui ipsam Artem velit vel possit complete discere vel habere. Et quia dies iam veniunt, ut funis argenteus dirumpatur, doleo, quod talis Ars nobilis, nulli thesauro comparabilis, omnino perdatur» (1).

O seu roteiro espiritual é o reflexo da insatisfação apostólico-intelectual. Após trinta anos de vida mundana, deu conta do vazio existencial que o torturava e converteu-se. Era o ano de 1266. Oito anos mais tarde, deixou o mundo para se entregar totalmente a Deus, na vida consagrada. Foi difícil a concretização do seu estatuto vocacional: bateu à porta de vários conventos. Após muitas hesitações, sobretudo entre as Ordens Dominicana e Franciscana, acabou por ligar-se definitivamente à Ordem Terceira de S. Francisco.

A luta denodada para conseguir o que ele queria e como queria, levou-o a desenrolar a sua vida um pouco por toda a parte: Palma de Maiorca (onde nascera em 1235), França, Itália, Norte de África e Médio Oriente. Tudo deixa, tudo sacrifica para se consagrar totalmente ao ideal proposto. Dirige-se para a cúria dos Papas, para o palácio dos Príncipes e para a cátedra das Universidades, na mira de todos conquistar para a sua causa e de lhes arrancar os meios humanos e materiais de que necessita. Em confissão de sabor paulino, ele próprio nos dá enfaticamente conta do que foi o frenesi da sua existência: «Homo fui in matrimonio copulatus, prolem habui, competenter dives, lascivus et mundanus; omnia ut Dei honorem, et bonum publicum

(1) Liber Natalis, in Raim. Lul. Op. Lat., ed. cit. t. 7 (1975), p. 72; 
possem procurare, et sanctam fidem exaltare, libenter dimisi, Arabicum didici, pluries ad praedicandum Saracenis exivi; propter fidem captus fui, incarceratus, verberatus; Quadraginta quinque annis ut Ecclesia rectores ad bonum publicum, et christianos Principes movere possem, laboravi: nunc senex sum, nunc pauper sum, in eodem proposito sum, in eodem usque ad mortem mansurus sum, si Dominus ipse dabit» (1).

\section{I - UM EPISÓDIO USADO COMO ESTRIBILHO}

Narra Raimundo Lulo um encontro de Raimundo Martí com o rei de Túnis em cinco dos seus livros, todos eles escritos em Montpellier, o que quase nos faz pensar numa certa perturbação incontida do autor ao aproximar-se de Barcelona, onde a influência de Martí, que aí passara uma grande parte da sua vida, devia ser ainda muito forte. Os livros em questão são:

Blanquerna (2), escrito provavelmente em 1283;

Disputatio Fidei et Intellectus (3), de 1303;

Convenientia Fidei et Intellectus (4), de $1304($ ?);

Liber de Fine (5), de 1305 (?);

Liber de acquisitione Terrae Sanctae, ( $\left.{ }^{6}\right)$ de 1310.

Como vemos, entre a primeira narração e a última medeiam 27 anos. Os pontos fulcrais são os mesmos em todas as obras, à excepção de Blanquerna, mas à medida que o tempo avança, Lulo sente necessidade de acrescentar novos elementos, certamente desnecessários quando se estava ainda próximo dos acontecimentos. Os dois últimos textos, seguindo uma exposição paralela, completam-se mutuamente com pormenores não despiciendos. Porque, por um lado, seria maça-

(1) Disputatio clerici et Raymundi phantastici, ed. Guiot de Marchant, Paris 1499, ap. G. Golubovich, o.c., p. 388;

(2) Blanquerna, cap. 84, n. 5; ed. Miguel Batllori y Miguel Caldentey, Madrid (B.A.C.) 1968, p. 432;

(3) Disputatio, ed. cit., p. 2;

(4) Covenientia, ed. cit., p. 4;

(5) De Fine, ed. cit., pp. 52-55;

(6) De Acquisitione, ed. cit., pp. 276-277; 
dora a inclusão aqui de todos os textos e, por outro, não são de fácil acesso ao leitor normal, transcreveremos integralmente os cinco em apêndice, tentando reconstituir agora $o$ episódio tal como Lulo o imaginava. Servir-nos-emos, para tanto, do Liber de acquisitione Terrae Sanctae como texto fundamental, completado pelos restantes:

"Conta-se que (ainda não há muito tempo) (1) um certo cristão religioso, bom conhecedor da (história) (2) e língua árabe, foi a Túnis disputar com o rei chamado Miramoli.

Aquele religioso [porque não era muito esclarecido em ciências lógicas e naturais, embora o fosse bem e competentemente em ciências morais, provou (em árabe) (3), em função de tal moralidade] (4), por costumes e exemplos, que a (Fé) (5) e a lei de Maomé eram erróneas e falsas, (coisa fácil de provar) (6).

«O dito rei sarraceno, que era conhecedor das ciências lógicas $e$ naturais, compreendeu que as provas eram verdadeiras; concordou com as suas palavras (e disse que aprovaria a Fé dos cristãos) (7). Afirmou ainda: "Não mais quero ser sarraceno; contudo, prova-me a tua Fé (por razões necessárias) (8) e far-me-ei cristão com todos os homens do meu reino, sob pena de decapitação. Então disse o religioso (que não era muito letrado em filosofia e em teologia) (9): «a Fé dos cristãos é tão alta que não pode provar-se (por razões necessárias); (10) apenas (se acredita) (11) (positiva e simplesmente) (12). Eis o Símbolo escrito em árabe. Acredita nele (e salvar-te-às) (13). O religioso dissera assim porque, embora letrado e moral, era apenas positivo e não probativo com razões.

(1) De Fine, ib.

(2) ib.

(3) ib.

(4) Convenientia, ib.

(5) ib.

(6) De Fine, ib.

(7) ib.

(8) Disputatio, ib.

(9) De Fine, ib.

(10) Disputatio, ib.

(11) De Fine, ib.

(12) Convenientia, ib.

(13) ib. 
«Então o rei disse (com malícia): (1): [Esta não é nenhuma prova; pelo contrário, tudo é positivo. Com efeito (2) eu não trocaria o crer pelo crer, mas de muito bom grado trocaria o crer pelo compreender a verdade. Portanto fizeste (muito) (3) mal porque reprovaste a lei que tinha e agora não podes provar-me com razões a tua, enquanto eu fico sem lei (já que) (não sou cristão, nem sarraceno, nem judeu)] ( ${ }^{4}$ ).

«Então o rei (fê-lo vilipendiar) (5) e expulsar desonestamente com todos os companheiros do seu reino (6). Eu vi este religioso e os seus companheiros (e falei com eles) (7).

"Além disso, aquele religioso sabia falar hebraico e disputava frequentemente em Barcelona, entre outros, com um certo judeu muito letrado e mestre em hebraico. Este judeu contou-me algumas vezes que repetidamente dissera àquele religioso que, se lhe prometesse compreender na sua Fé aquilo em que acreditava, se faria cristão. O religioso respondia que não poderia compreender, razão porque o judeu continuou como antes, desprezando a nossa lei como improvável e não verdadeira.

"Narrei aqui todas estas coisas pelo seguinte: com efeito, se o supra-citado religioso soubesse dar razões concluentes e insolúveis (8) acerca da nossa Fé, de maneira que o rei não podesse resolvê-las (essas razões estão implícitas na Sagrada Escritura ( $\left.{ }^{9}\right)$ e estou certo que se encontram nos meus supra-citados livros como se pode ver nos mesmos) (10), ter-se-ia feito cristão aquele rei e, consequentemente, muitos outros, como disse (11). Com efeito, o santo rei Luis de França foi por esse tempo a Túnis com o seu grande exército e se o predito rei dos sarracenos tivesse estado de acordo, toda a sua pátria seria já fiel e assim

(1) De Fine, ib.

(2) Convenientia, ib.

(3) Disputatio, ib.

(4) Convenientia, ib.

(5) ib.

(6) Aqui termina a Disputatio.

(7) Convenientia, ib.; esta obra só retoma o final da narração.

(8) Rationes Cogentes;

(9) Sacra Pagina;

(10) De Fine, ib.

(11) O De Acquisitione e o Convenientia terminam aqui para continuar a narração apenas o De Fine historicamente precioso e que não foi ainda explorado, que me conste, em relação a este tema. 
seria recuperada a Terra Santa (1). Considere portanto a consciência ter uma sentença contra aqueles que podem fazer o bem e para isso são designados e não só o não fazem como até é quase por eles profundamente negligenciado)» (2).

\section{II - CARACTERIZAÇÃo DO EPISÓDIO E SEUS INTERVENIENTES}

Uma breve análise dos textos não deixará de nos fornecer elementos interessantes para o conhecimento dos personagens em causa, bem como do ambiente intelectual que então se respirava, das relações tensas que envolviam a polémica religiosa islamo-cristã e dos diferentes métodos de pregação missionária.

O episódio narra, como é evidente em todos os apontados textos de Lulo, um encontro de carácter polémico-religioso, efectivamente realizado entre Ramón Martí e o rei de Túnis. Não podemos duvidar da sua historicidade; a quíntupla narração do mesmo seria ridiculamente desonesta se o não fora. Além disso, depreende-se do «ulterius dico et etiam juro» com que inicia a narração do episódio seguinte tal como é expresso no Liber de Fine, expressão que garante a veracidade do autor acerca dos dois episódios.

À partida, nada nos faz supôr que não se tratasse de um encontro amistoso. E há documentos históricos que nos falam explicitamente da amizade existente entre os dois protagonistas. Precisamente três anos após a redacção do Liber de acquisitione Terrae Sanctae (em Março de 1310), o cronista dominicano Pedro Marsílio, na célebre

(1) Neste livro, o De Fine, expõe Lulo pormenorizadamente, tal como o faria 5 anos mais tarde, no De Acquisitione, a estratégia bélica que, segundo ele, arruinaria totalmente o império árabe. A invasão cristã devia começar pela Andalusia, e avançar depois sobre a África e, mais concretamente, sobre Túnis, porta fácil para a entrada no Egipto e na Terra Santa. É este o significado global que dá à tão desejada conquista de Túnis por Luís IX de França, em 1270, e que corresponde, de facto, aos planos do rei francês: «quod prius irent ad expugnandum regnum Tunicii, antequam in Terram Sanctam, sive in Aegiptum transirent». Godofredo Bellolloco, Vita et sancta conversatio piae memoriae Ludovici quandam Regis Francorum, in Recueil des Histoirens des Gaules et de la France, t. XX, ed. de P. Daunou e J. Naudet, Paris 1894, p. 21.

(2) De Fine, ib. 
Crónica de Jaime I (Abril de 1313), depois citada por Diago (1) e pelos historiadores posteriores, apresenta-nos Martí como amigo do dito rei, bem como de Luis IX de França e, por suposto, do de Aragão: «...Sancto Ludovico regi Francorum et ille bono regi Tunicii clarissimus et familiarissimus habebatur» (2). Tratava-se, pois, do encontro de dois intelectuais, cada um deles à sua maneira, facto que o próprio Lulo aceita.

O rei de Túnis a que se refere o escritor maiorquino é o célebre Abu Abdallah Muhammad I al-Mustansir (1249-1277), que em 1249 sucedera a seu pai Abu Zakariya Yahia I (3) (1228-1249) e que se fizera proclamar califa em 1253 com o reconhecimento de Meca cinco anos mais tarde. Daí o título de Emir dos crentes (amir al-mu'minin) com que Lulo a ele se refere mais tarde, ao chamá-lo Miramolinus, Murmiamoli e Miramoli, respectivamente no De Convenientia, no De Dine e no De Acquisitione. O perfil intelectual que Lulo nos desenha de al-Mustansir é o de um homem letrado, «perito em lógica e em ciências naturais» (4), em sintonia com a tradição intelectual de Túnis que, sobretudo a partir de Abu-Zakariya e até pelo menos ao fim do século XIII, era na África o último reduto da ciência, tal como um viajante culto desse tempo, El-Abderi, no-la apresenta, em palavras transcritas por George Marçais: «Si je n'étais pas entré à Tunis, j'aurais déclaré que la science n'avait laissé aucune trace en Occident» (5). Falando de al-Mustansir, diz André Julien: «Il menait une politique de prestige, aménageant avec faste la Qaçba de Tunis, créant des jardins magnifiques avec pièces d'eau dans la région de Tunis, s'entourant de lettrés et de poètes» (6).

(1) «Era por esso y por otras muchas y grandes prendas que tenía muy respectado de los Principes y Reyes, del de Tunez, del santo de Francia Luys, e del de Aragon don Jayme el Conquistador, y érales a todos ellos grandemente caro y familiarissimo». F. Diago, Historia de la Provincia de Aragón de la Orden de los Predicadores desde su origen hasta 1600, Barcelona 1599, liv. II, cap. XVI, fl. 137r.

(2) Pedro Marsilio, o. cit., fl. $161 \mathrm{v}$.

(3) Charles E. DufourcQ, La couronne d'Aragon et les hafsides au XIII ${ }^{a}$ siecle (1229-1301), in Analecta Sacra Tarraconensia, 25 (1961), pp. 63-64;

(4) Convenientia, ib.; cfr. De Acquisitione, ib.

(5) Georges MarçaIs, Les Arabés en Berberie du XI au $X I I I^{a}$ siècle, p. 430:

(6) Сh. Andre Julien, Histoire de l'Afrique du Nord, Tinisie-Algérie-Marroc, Paris 1952, pp. 137-138; 
Não há a mínima dúvida de que o personagem cristão descrito por Lulo é Ramón Martí. A caracterização é de tal maneira vívida e pormenorizada, que apenas falta dizer explicitamente o nome; só o não diz porque, por um lado, o pensador maiorquino tem nos seus escritos por sistema não dizer o nome autêntico dos seus personagens e, por outro, todo o leitor culto sabia perfeitamente a quem se referia, tanto mais que o episódio era conhecido, como o faz supôr o termo «narratur» com que inicia três relatos: a Disputatio a Convenientia e o De Acquisitione.

Quando Lulo escreveu Blanquerna, em 1283, ainda Martí era vivo. A partir do convento dominicano de Santa Catarina de Barcelona, para onde fora nomeado como professor de hebraico em 1281, irradiava por todo o mundo culto a sua fama de arabista e hebraista. Reside certamente aí a explicação do facto de no livro em questão, ao contrário de todos os outros, fazer apenas uma mera referência, de carácter anedóctico e num contexto que dispensava todos os pormenores já que era certamente muito conhecido dos seus leitores. Passados que foram vinte anos e mais, a situação era bem diversa. Com efeito, Martí tinha morrido havia quase duas décadas mas a sua presença moral era ainda muito forte nos meios intelectual e misionário, como parece depreender-se da expressão de Lulo «ainda não há muito tempo». Seja como for, o episódio já não era conhecido de muita gente, pelo que se tornava necessário, no pensar do «Doutor Iluminado» que não desistia de o proclamar aos quatro ventos para dele tirar partido em favor da sua «arte» das «razões necessárias», colori-lo de mais pormenores. Foi isso que fez, e cada vez com mais insistência, como já notámos, nas obras do primeiro decénio do século XIV, culminando precisamente no De Acquisitione Terrae Sanctae.

O perfil que Lulo traça de Martí comporta aspectos positivos e negativos. Embora o balanço final que se recolhe das suas palavras seja manifestamente negativo, é interessante notar como lhe reconhece uma profunda erudição árabe.

O De Acquisitione Terrae Sanctae e o Convenientia Fidei et Intellectus apresentam-nos Martí como bom conhecedor da história e língua árabe, língua em que recitou e entregou ao rei o «Símbolo» (1). Esta entrega do Símbolo escrito em árabe ao rei de Túnis, de que nos fala

(1) «Ecce symbolum in Arabico expositum»; De Acquisitione, ib. 
Raimundo Lulo, é portadora de uma sugestão demasiado rica e carregada de implicâncias históricas para poder ser analisada, ainda que brevemente, dentro do âmbito destas páginas.

O De Fine diz que o diálogo se desenrolou na língua do Corão. $\mathrm{O}$ conhecimento das línguas orientais, e em especial do árabe, era um dos pontos fortes do erudito dominicano. Dele dizia Pedro Marsílio, em palavras repetidas por Diago (1) e Sena Lusitano: (2) «Erat frater iste dignus memoriae Frater Raymundus Martini persona multum dotata, clericus multum sufficiens in Latino, philosophus in Arabico, magnus rabbinus et magister in Hebraico, et in lingua Chaldaica multum doctus» (3).

Martí fora um dos designados pelo capítulo provincial de Toledo de 1250 para 0 «Studium Arabicum» (4).

A obra de Ramón Martí está toda ela repassada de erudição islamo-árabe; textos do Corão e dos «hadices» de Bukhari e Muslim, bem como dos filósofos Alfarabi, Avicena, Algazali, Averrois... aparecem a cada passo. Para nos apercebermos disto, basta folhear a Explanatio Symboli Apostolorum e o Pugio Fidei (5), para não falar Vocabulista in Arabico editado por E. Schiaparelli (6) que o atribui ao grande arabista do século XIII, e das Sumas contra os Sarracenos (7) de que fala

(1) F. Diago, o. cit., fl. 137 r.

(2) António de Sena Lusitano, Bibliotheca Ordinis Fratrum Praedicatorum..., Paris 1685 , p. 206:

(3) P. Marsilio, o. cit., fl. 161 v.

(4) Celestino Douals, Acta Capitulorum Provincialium Ordinis Fratrum Praedicatorum, Toulouse 1894, p. 612; cfr. F. Diago, Historia del B. Cathalan Barcelones S. Raymundo de Peñafort..., Barcelona 1601, fl. 95. Abstêmo-nos aqui da polémica tecida à volta da identificação do Studium Arabicum em questão que uns dizem ter sido o de Múrcia, outros o de Maiorca e outros o de Túnis. Noutro lugar nos pronunciamos com vasta documentação pelo de Túnis.

(5) Uma breve análise da erudição islamo-árabe pode ser lida em ANDRÉ BerthIER, Un maitre orientaliste du XIII siècle: R. Martin, in Arch. Fr, Praed., 6 (1936), pp. 295-304; ANgel Cortabarria, El estúdio de lenguas en la Orden Dominicana, in Estúdios Filosoficos, 19 (1970), pp. 363-366 e 372-379: cfr. ainda as obras de Miguel Asín Palacios, que têm sido a fonte inspiradora dos estudos sobre o tema.

(6) Vocabulista in Arabico publicado per la prima volta sopra un codice della Biblioteca Riccardiana de Firenze da E. Schiaparelli, Firenze 1871.

(7) «Fecit et diversa opera contra sectam Sarracenorum, eloquentia plena ac veritate fundata»; P. MARSILIO, o. cit., fl. $161 \mathrm{v}$. 
Marsílio e toda a tradição posterior e que é objecto principal de outro estudo de que o presente é apenas um trabalho monográfico propedêutico.

\section{III - MOTIVAÇÕES E FRAQUEZAS DA CRÍTICA LULIANA}

Já caracterizámos Lulo como um espírito radical que dificilmente aceitava processos de actuação não consentâneos com os seus próprios processos. É na crítica que ele faz àqueles processos que, por contraste, melhor podemos apreender os seus esquemas mentais, frequentemente nebulosos e quase sempre irrealistas, mesmo ao tratar de coisas tão vivenciais e "positivas» como eram a missionação dos muçulmanos e a exposição da fé cristã.

Ele, que pretendia impôr a todos os missionários o seu método e que fundou um colégio em Miramar onde, a par da aprendizagem da língua árabe e da filosofia, teologia e Sagrada Escritura, era ministrado o ensino da "Arte» por «razões necessárias», de forma alguma podia tolerar que o Norte de África muçulmano estivesse a ser envangelizado de acordo com o método das «razões positivas» que tanto detestava. Se isso lhe custara já durante a vida de Ramón Martí, muito mais lhe custou quando, com o andar dos anos, se deu conta de que o seu método estava votado a desaparecer com ele, como tivemos o ensejo de notar noutro lugar. Daí o seu despeito incontido que, como ideia fixa, tornou público em várias arremetidas: maneira pouco simpática de desviar as atençð̃es críticas dos seus contemporâneos do fracasso do seu método, fazendo-as incidir, através da narração de um simples episódio que coloriu à sua maneira, sobre a por ele suposta ineficácia intelectual e apologética de toda uma escola - a dominicana - encabeçada por Ramón Martí, o grande arabista e hebraista que plasmara geraçð̃es de jovens missionários no génio das línguas orientais, na solidez da apologética cristã e nos segredos da polémica com os judeus e muçulmanos. Com efeito, a voz e os escritos do douto dominicano eram a antítese do palavriado oco e tantas vezes sem sentido de um racionalismo inoperante e constituiam a reprovação implícita daquilo que caracterizava o grande projecto do "Doutor Iluminado»: a imposição de um método exclusivamente racional de que ele se considerava o autor.

Ao atacar frontalmente o método martiniano, Lulo sabia que atacava algo de válido e comunemente aceite; conhecia certamente os êxitos 
daquele grupo de dominicanos cultos e entusiastas que, por al-Andalus e Túnis convertia os muçulmanos aos milhares (1) e enchia de esperança as forças vivas da Igreja (2); conhecia a amizade que unia esses religiosos, e em especial Ramon Martí, a reis do cenário missionário como os de Aragão-Catalunha, França e Túnis; sabia certamente do apreço em que S. Raimundo de Penhaforte, o grande conhecedor e coordenador das actividades missionárias de Espanha e do Norte de África, incluindo, ao menos pontualmente, as dos próprios franciscanos (3), tinha os grandes apologetas dominicanos como Tomás de Aquino (4)

(1) A Vita Vetus (de S. Raimundo de Penhaforte), anterior a 1251, dizia, a propósito da conversão dos muçulmanos, condicionada pela aprendizagem do árabe: «...ex quo studio linguae arabicae fructus maximus est secutus, nam plures quam decem millia Sarracenorum a Fratribus eis praedicantibus sunt conversi, et inter Sarracenos de Hispania et etiam in Aphrica divulgata est veritas fidei christianae, et jam taliter approbata, quod multi eorum precipue sapientes dispositi sunt ad suscipiendam fidei catholicae veritatem». Raimundiana, in Monumenta Ordinis Fratrum Praedicatorum Historica, VI (1898), pp. 31.32; Cfr. Fr. Gerardo de Fracheto, Vitae Fratrum, ed. Reichert, in Mon. Ord. Frat. Praed., vol. I (1896), p. 310.

A Biografia de S. Raimundo de Penhaforte feita por Antist (1543-1599), tal como a vida do mesmo Santo escrita por Diago na sequência da crónica de Pedro Marsilio são portadoras do mesmo sentimento de admiração ao expressarem os mesmos elementos históricos. Cfr. Biografia inédita de San Ramón de Penyafort escrita por Vicente Justiniano Antist, O.P. (séc. xvI), ed. de Adolfo Robles Sierra, O.P., in Escritos del Vedat, 7 (1977), pp. 29-67);

(2) Cfr. bula de 15 de Julho de 1260, onde Alexandre IV se congratula com S. Raimundo pelo "frutrum non modicum» dos seus missionários entre os infieis, mormente entre os sarracenos. Ver o texto in Bullarium Ordinis Fratrum Praedicatorum, ed. Brémond, v. I, Romae 1729, p. 395;

(3) Cfr. a carta em que S. Raimundo, em 1234, resolve, em nome do Papa, as dúvidas apresentadas pelos superiores dos dominicanos e dos franciscanos do reino de Túnis e que inicia com a seguinte dedicatória: «Dilectis in Christo fratribus N. priori de Ordine Predicatorum et ministro fratrum Minorum in regno Tunicie commorantibus, frater R., domini Pape penitentiarius, salutem in Domino». Ed. Balmes Paban, Raymundiana, in Mon. Ord. Fr. Praed. Hist., VI-2 (1901), pp. 29-37; cfr. ainda a bula cit. na nota anterior;

(4) «Convertionem etiam infidelium ardenter desiderans frater Raymundus de Penyafort, rogavit doctorem sacrae paginae, magistrum in theologia Fratrem Thomam de Aquino, eiusdem Ordinis, qui inter omnes huius mundi clericos post Fratrem Albertum philosophum, maximus habebatur, ut opus aliquod faceret contra infidelium errores, per quod et tenebrarum tolleretur caligo et veri solis doctrina credere nolentibus panderetur. Fecit magister ille quod tanti patris humilis deprecatio requirebat, et Summa quae contra gentiles intitulatur condidit, quae pro illa mate- 
e Ramon Martí (1),a ponto de lhes encomendar livros que pudessem servir de texto para os «Studia Linguarum» e para a pregação missionária; conhecia certamente as obras do subiratense, em especial a Explanatio Symboli, o Pugio Fidei o Capistrum Judeorum e as Summas contra Alcoranum. Pois bem, é tendo como pano de fundo este contexto bem concreto, que devemos analisar o episódio em questão que, à distância de quase sete séculos, nos define duas personalidades diametralmente opostas e nos fornece elementos históricos preciosos para o conhecimento da vida de Ramon Martí.

Raimundo Lulo não podia aceitar que um método de pregação missionária que tão apaixonadamente condenava pudesse ter o sucesso que lhe atribuem os documentos da época a que já aludimos, sucesso que ele certamente não desconhecia; não podia sobretudo pensar, como deixa transparecer nos seus escritos, que aquele sucesso pudesse ocasionar a rejeição do seu próprio método. Havia, pois, que desfigurar de alguma maneira a obra dos seus «competidores», atacando frontalmente o seu líder. Reside aqui, penso, a razão de ser da quíntupla narração do episódio que nos ocupa.

Podemos sintetizar assim a oposição dos dois métodos: segundo Lulo, a conversão dos infiéis passa quase exclusivalente pela "Arte» que só ele conhecia (2), arte que se desenvolve por razões necessárias; segundo Martí, «a fé dos cristãos é tão alta que não pode provar-se (3) por razões necessárias $\left({ }^{4}\right)$; apenas se acredita $\left(^{5}\right)$ positiva e simplesmente (6). "A conversão dos infiéis está, pois, condicionada, segundo

ria non habuisse parem credatury. Pedro Marsílio, Cronice illustrissimi Regis Aragonum domini Jacobi victoriissimi principis, in Ms. 1018 da Bibliot. Central de Barcelona, Lib. IV, cap. 47, fl. 179 r.

(1) Vivendo durante largos anos na mesma casa, é natural que S. Raimundo de Penhaforte pedisse ao grande mestre dos estudos semitas, Ramón Martí, a colaboração para o efeito. No Proemium do Pugio Fidei diz explicitamente que o escreveu por obediência. Cfr. Pugio Fidei Adversus Mauros et Judaeos, Lipsiae 1787, p. 3, n. III;

(2) Ver a justificação desta afirmação em toda a primeira parte do presente estudo.

(3) De Acquisitione, ib.

(4) Disputatio, ib.

(5) De Fine, ib.

(6) Convenientia, ib. 
Martí, pela fé, expressa no Símbolo: (1) «Eis o Símbolo escrito em árabe; acredita nele e salvar-te-às».

Ao valorar e condenar moralmente Martí no final da narração, Lulo duvidava da sua honestidade científica e apostólica ou, ao menos, julgava-o ignorante em relação ao método das razões necessárias. Com efeito, o fundamento da atitude mental de Martí não estava, segundo Lulo, no facto de pensar que era a fé o caminho mais directo para a conversão dos muçulmanos mas sim, no facto de ele não conhecer as rationes necessariae: Martí «não era muito fundado em ciências lógicas e naturais (2) ... não era muito literato em filosofia e teologia (3); era só positivo e não probativo com razões $\left({ }^{4}\right) \ldots$ Com efeito, se o supra-citado religioso soubesse dar razões de tal maneira concludentes (rationes cogentes) e insolúveis acerca da nossa fé que o rei não podesse resolvê-las... ele ter-se-ia feito cristão...» (5)

Se entendermos por ciências lógicas e naturais aquilo que Lulo entendia e exprimia através da sua visão estereostática e desincarnada da realidade, estamos de acordo: Martí não era filosófico nem cientista. Se, ao contrário, entendermos por elas uma visão realista, humanista e humanizante do mundo, dos homens e de Deus, visão que manifestou através das suas obras em que, numa perspectiva de polémica religiosa, incarnava a situação concreta dos seus opositores a ponto de penetrar decididamente no campo deles, ao nível linguístico, filosófico e até religioso, para aí os atacar (6), então Lulo enganou-se redondamente porque, nesse sentido, Martí era filosofo. Assim o entenderam, além dos cronistas Marsílio e Diago já citados, Sena Lusitano (7) Altamura (8), Touron (9) e tantos outros a eles contem-

(1) De Acquisitione, ib.; Convenientia.

(2) De Acquisitione, ib.

(3) De Fine, ib.

(4) De Acquisitione, ib.

(5) De Fine, ib.

(6) Uma das estratégias polémicas de Martí, tanto em relação aos muçulmanos como aos judeus, é, como pode ver-se frequentemente explícita nas suas obras, a de atacar o adversário no seu próprio campo.

(7) «... in saeculari philosophia et divina valde eruditus»; A. Sena Lusitano, o. cit., pp. 206-207.

(8) «Fuit hic Martinus Philosophus acutissimus, ac Theologus non secundus». Ambrosio de Altamura, Bibliothecae Dominicanae, Romae, 1677, p. 58.

(9) R. Martin «tient un rang distingué parmi les Docteurs Catholi- 
porâneos e posteriores, numa cadeia que vem até aos nossos dias.

Martí, repetimos, não era certamente filósofo no sentido exclusivamente racionalista que muitos teimam em dar à filosofia. Ele fizera uma opção na vida: a de ser missionário entre os judeus e muçulmanos; essa opção fora-lhe proposta ou ratificada pelos superiores da sua Ordem que o designaram para os estudos bíblico-corânicos, linguísticos e teológicos. Esses estudos, que recebeu e assumiu dentro dos esquemas intelectuais e pastorais da mesma Ordem e para cujo incremento contribuiu depois como talvez nenhum outro, deram os frutos pastorais e intelectuais a que já nos referimos.

Além disso, é falsa a insinuação luliana de que Martí era "só positivo e não probativo com razões». Com efeito, ele soube casar maravilhosamente os dados da razão e da fé de acordo com a concepção unitária da ciência da época em que a filosofia não podia ficar separada do contexto teológico. Martí encarou, tal como Alberto Magno e Tomás de Aquino, a filosofia como fundamento racional da teologia, numa síntese harmoniosa que incluia as filosofias grega e árabe, síntese que está na base do florescimento da escolástica cristã.

Toda a sua obra documenta esta afirmação. Para nos atermos à problemática e ao contexto dos textos em análise do filósofo maiorquino, vejamos isso mesmo, por exemplo, na Explanatio Symboli, a propósito da demonstração do mistério da Ss. Trindade, em que o autor tenta adaptar-se a dois tipos de leitores: aos infiéis e aos fiéis. Começa por expôr o princípio: «Et hoc mysterium Ss. Trinitatis potest ostendi, primo per auctoritates; quia probatio per auctoritates in hac materia fortior est et certior fidelibus. Deinde rationibus et similitudinibus quoquo modo. Sciendum est autem in principio, quod loqui de Trinitate difficilimum est, eo quod supra intellectum est, non solum humanum, verum etiam angelicum...» (1)

De acordo com este princípio, traça depois o plano que efectiva e longamente vai seguir: «Verum, quia auctoritates sacrorum librorum non omnes recipiunt sapientes, tam fideles communiter quam infideles

ques... La solidité, et la pénetration de son esprit, on peut dire même la beauté de son génie, ne parurent pas moins que son éloquence...

A. TOURON, Histoire des hommes illustres de l'Ordre de saint Dominique t. I, Paris 1743, p. 490.

(1) Explanatio Symboli, p. 457, 34-38. 
rationibus acquiescunt, rationes aliquas post auctoritates ad ostentionem sanctae trinitatis in medium proponemus» (1).

É nisto que reside a causa, respectivamente, do sucesso missionário do método de Martí e do insucesso do de Lulo: na adaptação ou não adaptação aos destinatários, da sua mensagem. $\mathrm{O}$ método de Ramón Martí foi a realização plena dos principios magistralmente propostos por S. Tomás: «Contra singulorum autem errores difficile est procedere, propter duo: Primo, quia non ita sunt nobis nota singulorum errantium dicta sacrilega ut et his quae dicunt possimus rationes assumere ad eorum errores destruendos. Hoc enim modo usi sunt antiqui Doctores in destructionem errorum gentilium, quorum positiones scire poterant quia et ipsi gentiles fuerant, vel saltem inter gentiles conversati et in eorum doctrinis eruditi. Secundo, quia quidem eorum, ut mahumetistae et pagani, non conveniunt nobiscum in auctoritate alicuius Scripturae, per quam possint convinci, sicut contra Judaeos disputare possumus per Vetus Testamentum, contra haereticos per Novum. Hi vero neutrum recipiunt.

"Unde necesse est ad naturalem rationem recurrere, cui omnes assentire coguntur. Quae tamen in rebus divinis deficiens est. Simul autem, veritatem aliquam investigantes, ostendemus qui errores per eam excludantur, et quommodo demonstrativa veritas fidei christianae religionis concordet» $(2)$.

Não devemos radicalizar situações e muito menos "canonizar» escolas ou sistemas intelectuais e pastorais, mas podemos perguntar: qual deu mais frutos, a «escola» dominicana (3) com nomes como

(1) Ib., p. $457,50-53$.

(2) Summa contra Gentiles, I, 2.

(3) Ao fazer a generalização, aqui e noutras partes, da figura de Ramón Martí para a Ordem dos Dominicanos, estamos plenamente conscientes de não incorrer em erro lógico porque estamos certos de que aquele dominicano foi atacado, aliás anonimamente, por Lulo como bandeira, pois o seu objectivo mais fundo era atacar o método de toda a Ordem. Também queremos deixar aqui bem expresso que não pretendemos de forma alguma atingir a Ordem de S. Francisco, de que Lulo era "Terceiro», pois que também ela não embarcou nas suas águas e conhecemos o valor científico-missionário do seu método apologético. Isto também não quer dizer que o filósofo maiorquino não se tenha inspirado em pensadores franciscanos que, como Rogério Bacon, defendiam a possibilidade de provar os mistérios com razões necessárias»; cfr. JUAN TUSQUETS, Relación de Ramón Lull con San Ramón de Penyafort y con la Orden de Santo Domingo, in Escritos del Vedat, VII (1977) p. 185. 
Alberto Magno, Tomás de Aquino, Ramón de Penhaforte e Ramón Martí ou o sistema que não chegou a fazer escola, de Ramón Lulo, de que se cumpriu à risca o pressentimento pessimista das «lamentaçð̃es» a que já aludimos e que está subjacente a toda a sua obra, isto é, o pressentimento de que iria ficar só e sem continuadores no seu campo de batalha? Quem tem razão, Lulo que critica ou Martí que é criticado? Vale a pena, para levar até ao fundo a questão, explorar um pouco mais o texto.

Lamentava-se Lulo de que o rei de Tunis se não tivesse convertido por causa da já apontada inépcia do missionário dominicano e que tê-lo-ia feito se lhe tivesse arguido com as rationes cogentes et insolubiles que dizia terem fundamento bíblico e estarem contidas nos seus livros. Se Lulo tivesse escrito este argumento no primeiro dos livros citados, Blanquerna, seria de desculpar; mas escrevê-lo precisamente nos dois últimos, o Liber de Fine e o Liber de Acquisitione Terrae Sanctae, respectivamente em 1305 e 1310, quando já tinha passado pelas experiências de 1291 (ou 1292) em Túnis e de 1306 em Bugia, experiências de que tanto se lamentaria nas suas obras, isso ultrapassa os limites do bom senso, se é que não da honestidade moral. Perguntamos ainda: porque não converteu ele com as suas "oportuníssimas" rationes necessariae, cogentes et insolubiles, que dizia possuir como ninguém, o também hafsida Abu-Hafs Omar I, irmão de Al-Mustansir e que reinou em Túnis de 1284 a 1295 e o Abu-1-Baqá khalid I, soberano de Bugia, que restabeleceu a unidade hafsida em 1309? Isto para não falarmos do que lhe aconteceu na última viagem à África, em 1314/15, em que a glória do martírio aí começado lhe veio a apagar imprudências e presunções difíceis de compreender em análise desapaixonada e serena que não tenha em conta o aspecto religioso do problema.

Neste contexto, sabe a ridículo o ditame condenatório com que Lulo pretende atingir os dominicanos, não já apenas em relação ao método ou estratégia de missionação, como também em relação à própria honestidade moral. É expressiva a diatribe com que no $D e$ Fine os condena: «Et ideo conscientia spectet habere judicium contra illos, qui possunt agere bonum, et ad hoc deputati sunt, et non agunt, et quasi ab illis penitus est negletum» (1).

A aversão de Lulo aos dominicanos vinha já de muito longe. O célebre episódio da «tentação de Génova» (1292), narrado pela

(1) De Fine, ib. 
Vita Coetanea, dá-nos o porquê dessa aversão: os dominicanos, ao contrário dos franciscanos, rejeitavam a sua Arte. Isto levou-o mesmo a preferir o hábito franciscano ao dominicano, apesar da visão em que diz ter ouvido as palavras vindas de uma estrela que lhe aparecera no tecto do seu quarto: «Nesta Ordem (dos Pregadores) podes salvar-te». O cronista diz explicitamente: «Raimundus igitur, considerans hinc sui damnationem, nisi ipse cum Praedicatoribus, hinc Artis et librorum, quos fecerat, perditionem, nisi ipse cum fratribus Minoribus moreretur, elegit, quod erat supermirabile, damnationem sui ipsius aeternam potius, quam quod Ars praedicta, quam noverat se recepisse a Deo ad multorum salvationem et Dei honorem praecipue, perderetur». Et sic, non obstante reclamatione stellae praedictae, misit pro gardiano fratrum Minorum, a quo petiit eorum habitum sibi dari» (1).

São repassadas de verdade as palavras de Juan Tusquets ao afirmar: «El rigor dialéctico, la profundidad teológica, la bien merecida reputación misionera y académica de los dominicos eram incompatibles con la pretensión del improvisado Maestro mallorquin de que adoptasen su Ars Magna para formar a los futuros misioneros, inspirasen en ella y en sus derivados el temario de los sermones y el programa de las cátedras y se atuviesen a las orientaciones de Lull en la fundación y regimen de los Estudios de índole misional» (2).

Porque não queremos alongar-nos demasiado, afastando-nos da polémica islamo-cristã para entrarmos no da judio-cristã, que merece um estudo independente, prescindimos aqui da análise do penúltimo parágrafo do texto em que se fala de «um certo judeu muito literato e mestre em hebraico (3). Baste-nos, por ora, notar que se trata do célebre rabino Moisés de Gerona, isto é, Mosé Ben Nahman, também chamado Bonastrug de Porta.

\section{IV - PROBLEMAS CRONOLÓGICOS}

Não é fácil determinar com certeza quando ocorreu o episódio que nos ocupa já que, cronologicamente, pouco se sabe de Ramón

(1) Vit. Coet., e. cit., p. 287; cfr. Desconhort, estrofe XIV, Blanquerna, cap. XC.

(2) J. TusqueTs, a. cit., ib.

(3) De Acquisitione, ib. 
Martí e se sabemos bastante mais de Ramón Lulo, sobre este episódio paira uma certa nebulosidade. Há no entanto nas supra-citadas narraçð̃es, sobretudo nas do De Acquisitione Terrae Sanctae e no De Fine, elementos que nos vão ajudar a fazer um pouco de luz sobre o problema. Façamos aproximações:

O «ainda não há muito tempo» ( $\left.{ }^{1}\right)$ do Liber de Fine faz-nos pensar que não teria sido nos primeiros tempos da actividade missionária de Martí. Por outro lado, foi antes de 1283, primeira data em que Lulo cita o acontecimento, no Blanquerna. Mais concretamente, aconteceu entre 1249 e 1277, isto é, durante o reinado de Al-Mustansir. tal como vimos mais acima.

Com base certamente neste último elemento e apoiados apenas no De Acquisitione Terrae Sanctae, já alguns autores aventaram hipóteses que, creio, devem ser ultrapassadas. Assim, o facto de Raimundo Martí se encontrar em Barcelona em $1264\left({ }^{2}\right)$, como censor dos livros judaicos, não nos dá o direito de dizer que já tinha sido expulso de Túnis por causa do incidente referido por Lulo antes dessa data. Essa era a hipótese de P. Marc. (3).

Também não se vê claro a argumentação de Pedro Ribes y Montané ao afirmar: «La Explanatio Symboli Apostolorum la escrebió fray Ramón en Túnez en 1257 (ESA 473, 28), y, segun el testimonio de Ramón Lull, él mismo la tradujo al árabe y la presentó a Miramolin...» Parece-me demasiado simplista e pouco correcta esta explicação. Com efeito, a Explanatio não diz, como insinua o autor em questão, que foi escrita em Túnis: além disso, Raimundo Lulo nunca disse, nem no texto citado $\left({ }^{4}\right)$ nem noutro, que Martí traduziu para árabe a Explanatio; se a traduziu (e eu também quero crer que sim), é porque já existia em latim antes desse encontro de Túnis. Assim, ao certo,

(1) De Fine, ib.

(2) Martí foi nomeado por decreto de 20 de Março de 1264 por Jaime I censor dos livros dos judeus, juntamente com o bispo de Barcelona, S. Raimundo de Penhaforte, fr. A. de Segarra e fr. P. de Génova; cfr. Prospero de Bofarull y Mascaro, Colección de Documentos inéditos del Archivo de la Corona de Aragón, cuaderno 26, Barcelona 1850, pp. 164-165.

(3) Petrus Marc, Liber de Veritate Catholicae Fidei contra errores infidelium qui dicitur Summa contra Gentiles, t. I (Introductio), Turim (Marieti) 1967, p. 54, n. ${ }^{\circ} 4$.

(4) De Acquisitione, ib. 
sabemos que a Explanatio foi escrita em 1257, porque o autor o diz (1); que Martí entregou ao rei de Túnis o Símbolo em árabe; e que, na hipótese de se tratar da mesma obra, só depois dessa data (1257) terá sido entregue ao rei de Túnis.

Por outro lado, há dois textos lulianos, o De Acquisitione e o De Convenientiae, que dizem que o autor viu e falou com Ramón Martí e com os seus companheiros. É evidente que se trata de um encontro posterior ao episódio de Túnis, já que as narraçð̃es no-lo sugerem como fonte e autenticidade das mesmas. Mas quando, quantas vezes e onde se encontraram? Fazendo a aproximação das cronologias martiniana e luliana, não achamos dificuldade em supôr que foi fácil terem-se encontrado. A vida de Lulo foi de tal maneira agitada pelos caminhos da Europa e do Norte de África que deve ter tido a oportunidade de encontrar-se várias vezes com os companheiros de Martí e com ele próprio.

Barcelona e Montpellier eram os lugares mais propícios para esses encontros, dada a ligação cultural, geográfica, económica e política então existente entre essas duas cidades. Lulo estava muito ligado a Barcelona: em 1249 entrara como pagem do infante Jaime na corte que estava geralmente na cidade condal. Em 1257 casara com a barcelonesa Blanca Picany e era nomeado senescal do mesmo príncipe, sucessor de Jaime I no reino de Maiorca. Era natural que, ainda que não tenhamos dados certos, continuasse ligado àquela cidade, que aí se deslocasse e aí residisse temporariamente. Ao certo, sabemos que por volta de 1264 foi a Barcelona, onde se aconselhou com S. Raimundo de Penhaforte sobre a orientação a dar à sua vida. A Vita Coetanea diz-nos claramente que depois de ter feito uma peregrinação a vários mosteiros para pedir à Virgem e aos santos que o iluminassem, pensou ir estudar para Paris, ideia de que foi dissuadido pelos amigos e em especial por S. Raimundo (2). Com Eusébio

(1) «Cum igitur iam complete sint ille LXX ebdomades, sive sint dierum sive mensium, sive annorum, et amplius fluxerint MCCLVII anni...»; Explanatio Symboli, p. 473, 27-29;

(2) «Completa ergo peregrinatione sua praedicta, paravit iter arripere Parisius, causa discendi, ibi gramaticam et aliquam aliam scientiam, suo proposito congruam. Sed ab hoc itinere parentes et amici sui, et maxime frater Raimundus de Ordine Praedicatorum, qui quondam domini Gregorii noni compilaverat Decretales, suis persuasionibus et consiliis diverterunt, et eum ad civitatem suam, Maioricarum scilicet, redire fecerunt». Vit. Coet., e. cit., p. 278. 
Colomer, (1), sou de parecer que essa data é demasiado cedo, como veremos a seguir, para situar os acontecimentos que estamos analisando.

Mais viável nos parece poderem ter-se encontrado a quando das muitas viagens que Lulo fez posteriormente, sobretudo a partir de 1274/75, a Montpellier (2). Com efeito, sabemos que Martí se estabeleceu definitivamente em Barcelona em 1269. Que este se deslocasse a Montpellier ou Lulo a Barcelona, não era difícil encontrarem-se. A data de 1275, quando Lulo foi chamado a Montpellier pelo rei de Maiorca, parece-me poder conjugar-se com os factos anteriores a essa data que passo a apontar e em que reside, a meu ver, a chave do episódio de Túnis.

Diz Lulo no De Fine: "Tunc Rex fuisset christianus, et una cum eo suae gentes. Quoniam Sanctus Rex Franciae Ludovicus ivit tunc Tunicium, cum exercitu suo magno, et si praedictus Sarracenorum Rex consensisset, tota sua patria esset iam fidelis, et sic recuperata fuisset Terra Sancta».

O «tunc» do texto estabelece uma relação de contemporaneidade explícita e de causalidade implícita entre os dois acontecimentos: o encontro de Martí com Al-Mustansir e a cruzada de Luis IX contra Túnis em 1270. Historiadores há que defendem esse nexo causal, mesmo ignorando, ou ao menos não explorando o texto do De Fine. Assim Dufourcq, ao dizer: «Un grand mirage religieux apparut ainsi dès le XIII ${ }^{\mathrm{e}}$ siècle: assistant à la conversion de Musulmans au Christianisme dans les Baléares et dans le royaume de Valence, des sujets du Roi d'Aragon étaient particulièrement exposés à se laisser séduire par ce mirage; aussi n'est-il pas étonnant que le Dominicain catalan Ramón Martí (1200-1286) soit l'un de ceux qui, à la veille de la Croisade de 1270 , poussèrent particulièrement Saint-Louis à croire en la possibilité de la conversion au christianisme du souverain tunisien, qui était pourtant alors le Calife Al-mustansir (3).

(1) Testemunho colhido por carta que o erudito escritor se dignou escrever-me em 12 de Dez. de 1980.

(2) Cfr. M. BATllori, Vitae Coetanea (Introduction), in Obres Essensiels, I, Barcelona 1957, p. 40; S. Garcias Palou, El Miramar de Lull, e. cit., p. 41 ; S. Galmes, Dinamismo de Ramón Lull, Mallorca 1935, pp. 13-13.

(3) Ch. E. DufourcQ, a. cit., p. 65; cfr. Garcias Figueiras, Presencia de España en Bereberia central y oriental, Madrid 1943, p. 42; A. JULIEN, o. cit., p. 138. 
Os cronistas de Luis IX de França sublinham bem esse sonho de conversão dos muçulmanos que o acompanhou até à morte. Assim, o seu confessor e biógrafo, Godofredo de Belloloco: «Dicite ex parte mea domino vestro regi, quod ego tam vehementer salutem animae ipsius desidero, quod vellem esse in carcere Sarracenorum omnibus diebus vitae meae, ibidem claritatem solis non visurus de caetero, dummodo rex vester et gens sua ex vero corde fierent Christiani» (1).

Já vimos mais acima que os cronistas nos apresentam Martí como amigo do rei de França. Conhecedor como era aquele dos problemas tunisianos e da língua árabe, nada mais natural que tenha desempenhado, juntamente com S. Raimundo de Penhaforte, um papel muito importante nas relaçð̃es de Luis IX com al-Mustansir. Diz Berthier que «dès que $R$. de Penafort fut renseigné sur les préparatifes de la croisade, il dépêcha R. Martin en Afrique» (2).

Todos estes elementos estão de acordo com a cronologia apontada pela crónica de Pedro Marsílio que, como de costume, é seguido pelos cronistas posteriores da Ordem Dominicana. Ao descrever com linguagem grandiloquente os reveses da cruzada de Jaime I à Terra Santa e ao contar como foi a armada forçada a ancorar em Águas Mortas, diz o seguinte: «Exivitque ad terram ille qui equis praeerat: et invenit duos Fratres Praedicatorum in terra, qui tunc venerant Tunicio, videlicet Fratrem Franciscum Cineris, et Fratrem Raimundum Martini» (3). Corria o Outono do ano de 1269.

Tudo se apresenta agora mais claro: Em 1269, R. Martí estava em Túnis; aí serviu de embaixador de Luis IX de França e de S. Raimundo de Penhaforte junto do rei Al-Mustansir. Tentou convertê-lo. ao cristianismo, como refere Raimundo Lulo, mas não conseguiu. Entretanto, pairava já no ar a ameaça da cruzada de Luis IX (4) contra o Norte de África. Este punha-se em pé de guerra. Pressionados pelo contexto bélico, Martí e os seus companheiros, tal como todos

(1) GodofRedo DE Belloloco, O.P., Vita et sancta conversatio piae memoriae Ludivici quondam Regis Francorum, in Recueil des Historiens des Gaules et de la France, t. XX, ed. de P. Daunou e J. Naudet, Paris 1894, p. 21 ; cfr. Gesta Sancti Ludovici Noni, Francorum Regis, (anonimo), ib., p. 56; Guilherme De MANGiaco, Gesta Sanctae Memoriae Ludovici Regis Franciae, ib., pp. 460-461.

(2) A. BERTHIER, a. cit., p. 275.

(3) P. Marsilio, o. cit., fl. 161v.; cfr. F. Diago, Hist. Prov. Arag., fl. 137.

(4) Trata-se da derradeira cruzada de 1270. 
os europeus, devem ter tomado as devidas precauções e retiram-se. Isto explica a ilacção talvez hiperbólica de Lulo: «E então o rei fê-lo vilipendiar e expulsar desonestamente com os seus companheiros do seu reino (1).

É isto que quer significar Mas Latrie, que citamos: «L'expédition du roi de France avait donné l'alarme sur toute la côte d'Afrique, et les sujets des Etats chrétiens restés étranges à la guerre avaient cru prudent de s'éloigner momentanément du pays. A la paix, il y eut un égal empressement pour rétablir les communications antérieurs chez les Arabes et chez les Européens» (2).

De tudo isto, podemos concluir que o tão enigmático episódico de Ramón Martí com o rei de Túnis que Lulo tão malevolamente explorou contra a estratégia missionária dos dominicanos, deve ter-se efectuado em 1269.

Universidade de Évora, 1 de Julho de 1982.

JoAquim Chorão LaVAJo

(Bolseiro do I.N.I.C.)

(1) De Acquisitione, ib.; Disputatio, ib.; Convenientia, ib.

(2) MAS LATRI, Relations et commerce de l'Afrique setentrionale ou Magreb avec les nations chrétiennes au Moyen Age, Paris 1886, p. 252; ap. E. LONGPRE, a. cit. p. 271 ; cfr. Ch. E. JuLIEN, o. cit., p. 138. 


\author{
APÊNDICE DOCUMENTAL \\ O ENCONTRO DE RAMÓN MARTí COM O REI DE TÚNIS NA OBRA \\ DE RAIMUNDO LULO \\ 1 - Blanquerna
}

Cap. 84, n. ${ }^{\circ}$ 5; ed. Miguel Batllori y Miguel Caldentey, Madrid (B.A.C.), 1968, p. 432.

Hallándose el cardenal con sus oficiales delant del Papa a procurar su oficio, entró un sarraceno muy viejo y anciano, y presentó al Papa una carta de parte de un rey moro, con la qual le suplicaba le enviase a decir si era verdad lo que un cierto cristiano le había referido de la fe católica y había desenganado de la ley de Mahoma, en que estaba. Quería ser Cristiano; pero por quanto el cristianismo le decía que la fe católica no podía probarse con razones, pero esto dudaba en hacerse cristiano, porque no queria dejar una fe por otra. Pero decía que por inteligencia dejaría la fe de Mahoma y entraría en la católica, como el Papa de dijese que era probable; pues si lo era, él se haría cristiano y adoraría a Jesucristo como Diós y sujetaría todo su reino a la obediencia de la Iglesia romana, para que todos sus vasallos adorasen a Jesucristo.»

\title{
2 - Disputatio Fidei et Intellectus
}

(Pars I, ed. Salzinger, Opera Omnia, IV 8., Moguntiae 1729, p. 2).

«Sicut narratur, quod quidem Saracenus Rex peritus in Philosophia disputavit cum quodam Christiano, et Christianus probavit ei, quod Lex Saracenorum esset falsa. Tunc Rex dixit Christiano, quod ipsi probaret Christianam Fidem per necessarias Rationes, et sic faceret se Christianum cum omnibus Saracenis sui regni. Dicit autem Christianus, quod sua Fides non posset probari per necessarias Rationes.

Tunc ait Rex Christiano: tu valde male fecisti, quia eram Saracenus sed nunc sum nec Saracenus nec Christianus; et ipsum inhorabiliter vituperando expulit e suo Regno. Et sic videas, Fides, quam magnum damnum fuerit, quia Christianus te Fidem non probavit.»

\section{3 - Convenientia Fidei et Intellectus}

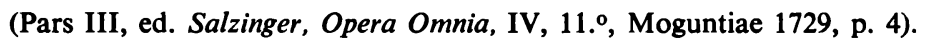

«Narratur quod quidem Rex Tunicii, qui Miramamolinus vocabatur, peritus in Logica et in Naturalibus, disputavit cum quodam Catholico Religioso valde bene sciente historias et etiam ita bene Arabicum, sed non erat bene fundatus in Logicalibus et in Naturalibus, sed in Moralibus bene et competenter, ratione cujus mora- 
litatis probavit illi Regi, quod Fides Mahometi esset erronea et falsa; et cognita ratione Rex concessit, nam erat rationabilis homo, ut dictum est; tunc ait Rex. imposterum non sum Saracenus, sed proba mihi, quod tua Fides sit vera, et ego faciam me Christianum cum omnibus hominibus mei Regni, et qui noluerit esse Christianus, decapitabitur. Tunc dixit Religiosus, Catholica Fides est tam alta quod non possit esse probabilis, sed positive et simpliciter declaravit ipsi Symbolum in Arabico, dicens: crede hoc, et salvaberis.

Tunc ait Rex, haec non est aliqua probabilitas, imo totum est positivum, et sic nolo dimittere credere pro credere, sed bene credere pro intelligere; et sic tu male fecisti, quia me evacuisti Fide, quam habebam, modo non sum Christianus, nec etiam Saracenus, nec Judaeus. Et tunc Rex fecit ipsum vituperari, et ejici illum Fratrem e suo Regno. Ego vidi Fratrem cum his Sociis, et fui locutus cum ipsis. Hoc narro propterea, quod si dictus Frater habuisset notitiam de modo probandi Articulos, sicut dedimus exempla in praecedenti Livro, ille Rex fuisset factus Christianus, et totum suum Regnum fuisset Christianorum Deo adjuvante.»

\section{4-Liber de Fine}

(in Divi Raymundi Lulli Martinis doctorisque divinitus illustrati Libellus de Fine, Palmae Balear. 1665, dist. I, pars V, pp. 52-55).

«Ulterius accidit, quod Tunitii fuit quidem Rex Sarracenus, qui Murmiamoli vocabatur; et adhuc non est diu, quod unus Religiosus Christianus arabice huic probavit quod Sarracenorum lex erat falsa, et hoc est facile ad probandum. Tunc Rex ei dixit, quod fidem Christianorum approbaret, et ipse deinde se faceret Christianum, et omnes alios de sua patria faceret baptizari. Dictus religiosus non erat multum litteratus in Philosophia, neque in Theologia, et respondit, quod Christianorum fides non erat probabilis, sed tantum credibilis. Et tunc pro trufa Rex habuit dicta sua, et quod nolebat credere pro credere dimittere dixit ei, sed bene dimitteret credere pro intelligere veritatem: et ideo si religiosus ille de nostra fide tales dedisset rationes, ita cogentes, quod Rex non posset solvere ipsas quae rationes sunt in sacra pagina implicatae, et sum certus quod in libris meis supradictis sunt, ut patet in eisdem. Tunc Rex fuisset Christianus, et una cum eo suae gentes; quoniam Sanctus Rex Franciae Ludovicus ivit tunc Tunicium, cum exercitu suo magno, et si praedictus Sarracenorum Rex consensisset, tota sua patria esset jam fidelis, et sic recuperata fuisset Terra Sancta, et ideo conscientia spectet habere judicium contra illos, qui possunt agere bonum, et ad hoc deputati sunt, et non agunt, et quasi ab illis penitus est neglectum.

Ulterius dico et etiam juro......» 


\section{5-Liber de Acquisitione Terrae Sanctae}

(ed. E. Longpré, O.F.M., in Criterion, 3 (1927, pp. 276-277).

«Narratur quod quidam christianus religiosus bene in arabico litteratus, fuit Tunicium disputandum cum rege, qui Miramoli vocabatur. Ille vero frater probavit ei per mores et exempla quod lex Mahometi erat erronea atque falsa; rex dictus sarracenus, qui in logicalibus et naturalibus erat sciens, cognivit istius probationes esse yeras, et sic consensit dictis eius dicens; "Abhinc nolo esse sarracenus, et proba michi fidem tuam et volo fieri christianus et sic volo de omnibus regni mei ut sub poena decapitationis omnes efficiantur christiani». Tunc ille frater: Fides christianorum non potest probari, sed ecce symbolum in arabico expositum; credas ipsum". Hoc dixit ille frater quia licet litteratus esset et moralis, positivus tantum erat et non cum rationibus probativus. Tunc rex dixit: «Ego non dimitterem credere pro credere, sed credere pro vero intelligere multum libens, et sic male fecisti, quia legem quam habebam, reprobasti postquam tuam michi non potes cum rationibus approbare, quoniam modo remanebo sine lege». Et tunc fecit illum cum suis sociis omnibus e regno eiici inhoneste. Istum fratrem et suos socios ego vidi.

Ulterius sciebat loqui hebraice ille frater, et inter alios cum quodam iudeo, valde in habraico litterato et magistro, Barcinone frequentius disputabat: qui ludeus aliquociens michi dixit quod pluries dixerat illi fratri quod si in fide sua promittebat se intelligere quod credebat, ipse se faceret christianum. Et frater respondebat quod intelligere non poterat, quare judeus remansit sicut erat spernendo legem nostram tanquam improbabilem et non veram.

Hec omnia propter hoc hic narravi: nam si predictus religiosus de fide nostra dare scivisset cogentes rationes et insolubiles a predicto ille factis fuisset christianus et per consequens plures alii, sicut dixi, quae rationes possibiles sunt reperiri, sicut certus sum et paratus sum demonstrare.» 